\title{
Nucleate Boiling Heat Transfer Investigation Using Micro and Nanostructured Plates
}

\author{
Masoumeh Nedaei $^{1}$, Nawzat Saadi ${ }^{2}$, Tansel Karabacak ${ }^{2}$, Ali Kosar ${ }^{1}$ \\ ${ }^{1}$ Mechatronics Engineering Program, Faculty of Engineering and Natural Sciences, Sabanci University \\ Tuzla 34956, Istanbul, Turkey \\ mnedaei@sabanciuniv.edu; kosara@sabanciuniv.edu \\ ${ }^{2}$ Department of Physics and Astronomy, University of Arkansas \\ Little Rock 72204, AR, USA \\ nxsaadi@ualr.edu; txkarabacak@ualr.edu
}

\begin{abstract}
In this study, heat transfer performance of micro and nanostructured plates embedded into a rectangular microchannel was experimentally investigated for their potential use in cooling applications. A simple and environmentally friendly technique was proposed to provide the micro and nanostructured plates having superhydrophilic property. Aluminium alloy (Al Alloy) 4041 substrates of $1.5 \times 1.5 \mathrm{~cm}$ were roughened by sandblasting method using medium size aluminum oxide abrasive to provide microfeatures; followed by hot water treatment (HWT) process in which nanograss structures were developed on the microstructured substrates. The micro and nanostructured plates were placed near the exit of an aluminum (Al) microchannel with a length, width, and depth of $14 \mathrm{~cm}, 1.5 \mathrm{~cm}$, and $500 \mu \mathrm{m}$, respectively. Four cartridge heaters connected to a DC power supply were utilized to apply heat to the test section. De-ionized (DI) water was used as the working fluid and passed through the microchannel using a micro gear pump at three mass fluxes of 100,300 , and $500 \mathrm{~kg} / \mathrm{m}^{2}$ s. The test section dimensions and experimental parameters were selected such that fully developed flow conditions were obtained. The results from the microchannel with untreated Al alloy surfaces were considered as the baseline data. Experimental results of the micro and nanostructured plates revealed that there is no significant change in nucleate boiling heat transfer compared to the control sample. The reason is related to wettability and roughness of the micro and nanostructured plates.
\end{abstract}

Keywords: micro and nanostructured plate, superhydrophilic plates, nucleate boiling, rectangular microchannel

\section{Introduction}

The performance and efficiency of many electronic devices and power applications [1]-[3] have been confronted with the obstacle of the ever-increasing heat generation. The liquid cooling techniques have received considerable attention as a promising solution for thermal management of the devices operated at high heat fluxes. One of the most applicable liquid cooling techniques is phase change in micro/nanoscale, especially during nucleate boiling that offers a favorable solution for achieving high heat removal rates. The small increase in wall superheat with heat flux during nucleate boiling region leads to high heat removal rates. Many researchers have been therefore suggested various methods to utilize nucleate boiling and to achieve higher heat transfer rates, in particular by altering the heating surface characteristics such as modifying surface roughness and wettability or by tuning the liquid's properties.

In order to investigate the effects of surface roughness, Berenson et al. [4] studied pool boiling of n-pentane at atmospheric pressure. The result showed an increment of 5-6 times in the nucleate boiling heat transfer coefficient using roughened surfaces. Benjamin and Balakrishnan [5] performed pool boiling experiments of different liquids including distilled water, acetone, n-hexane, and carbon tetrachloride through surfaces with various roughnesses constructed by polishing. Their results revealed strong dependence of nucleation site densities on the surface roughness. Alam et al. [6] investigated flow boiling of water over silicon microgap heat sinks in three different surface roughnesses. Their results showed that higher heat transfer rates could be obtained from the surfaces with higher roughness and larger microgap heat sink. The objective of applying surface modifications is to tune boiling heat transfer characteristics. The results available in the literature are conflicting with each other as Wasekar and Manglik [7] mentioned in their review. Some of the studies showed enhancement in heat transfer [8]-[11] while some other demonstrated degradation [12]-[14]. There are also studies 
that stated no significant change in heat transfer coefficient [15], [16]. For example, Ammerman and You [8] examined flow boiling of FC-87 in a small channel enhanced by microporous coatings. Their results revealed enhancement in nucleate boiling by over $300 \%$ with application of microporous coated channels. Sun et al. [11] studied effects of enhancing minichannels in different hydraulic diameters by microporous coatings on flow boiling of FC-72. They reported that heat transfer was substantially increased with microporous coated minichannels compared to their bare surface counterparts reaching a maximum enhancement of 7-10 times. In the previous work of the authors [9], initiated chemical vapor deposition (iCVD) method was used for coating inner walls of the microtubes with polyhydroxyethylmethacrylate (pHEMA)/polyperfluorodecylacrylate (pPFDA) to investigate flow boiling of water. The pHEMA/pPFDA coatings provided high porosity and variation in wettability along the surface of the microtubes. Both configurations of pHEMA (hydrophilic) inlet and pPFDA (hydrophobic) outlet and vice versa were examined to investigate the effects of wettability. The results showed augmentation in boiling heat transfer by using the coated microtubes with a maximum enhancement of $\sim 64 \%$ for the pHEMA coated outlet case. Recently, Shojaeian et al. [12] studied nucleate boiling of aqueous Xanthan gum solutions in various concentrations. They reported a deterioration in heat transfer coefficient with polymeric solutions compared to pure water. Phan et al. [13] investigated flow boiling of water in rectangular microtubes with different nanocoatings with water contact angles of $26^{\circ}, 49^{\circ}, 63^{\circ}$, and $104^{\circ}$. Their results proved considerable impacts of wettability on heat transfer performance. They found that using hydrophobic surfaces, nucleate boiling initiated at a temperature lower than the saturation one, while hydrophilic surfaces had a worse heat transfer performance. Zhang et al. [14] studied boiling heat transfer of (non)ionic liquid polymers through hydrophilic/ hydrophobic alumina sponge-like nanoporous surfaces. They observed that there is an optimal concentration and heat transfer rate was reduced for the concentrations larger than this value. However, in the studies done by Yang et al. [15] and Paul and Abdel-Khalik [16], they reported that nucleate boiling heat transfer was remained unchanged by using polymer additives.

This study investigates nucleate boiling heat transfer of the micro and nanostructured plates located into a rectangular microchannel. A simple and environmentally safe method was employed to produce the micro and nanostructured plates with strong wettability. The experiments conducted at three mass fluxes of 100,300 , and $500 \mathrm{~kg} / \mathrm{m} 2 \mathrm{~s}$ while de-ionised water was used as the working fluid.

\section{Micro and Nanostructure Fabrication Process}

Al alloy 4041 substrates were utilized for constructing the micro and nanostructured plates with superhydrophilic property. The reason for utilizing this material was the extensive use of $\mathrm{Al}$ alloy in industry due to its light weight and mechanical robustness that when combined with superhydrophilic property, it can be implemented in a wide range of industrial applications [17], [18]. Commercial Al plates (Alloy \#4041) were first polished by sanding using ultra fine sandpaper of 5000 grits to remove native oxide layers and other organic contaminations. For control sample, the polished plates were cleaned by sonication in Acetone, Isopropanol, and DI water for 10 minutes, respectively, followed by Nitrogen gas purge to dry the samples. Micro and nanostructured samples were fabricated by engraving microfeatures on a polished plate by using sandblasting method. The sandblasting process were performed using medium size aluminum oxide abrasive for 10 seconds. Thereafter, the sandblasted plates cleansed by sonication process in Acetone, Isopropanol, and DI water for 10 minutes, respectively, to clean the surface from abrasive residuals. Finally, the cleaned microfeatured plates were integrated with nanograss structures through hot water treatment (HWT) process. The HWT process carried out by placing the plates in a pyrex beaker filled with ultra-pure DI water for 10 minutes, while the water temperature was kept at $75^{\circ} \mathrm{C}$ during the HWT process.

Figure 1 illustrates water contact angles of the control and micro and nanostructured plates, which were measured using the Theta Lite Optical Tensiometer TL100 device. The contact angles corresponding to the micro and nanostructured and untreated plates were measured as $\sim 1.5^{\circ}$ and $\sim 76.7^{\circ}$, respectively, indicating superhydrophilicity of the micro and nanostructured plates [19].

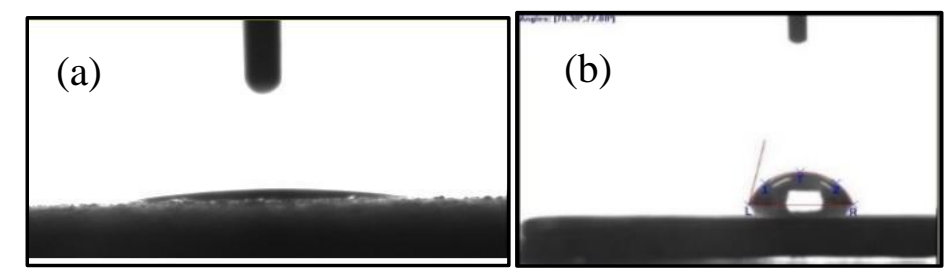


Fig. 1: Contact angles of (a) micro and nanostructured plate and (b) untreated plate .

In Fig. 2 Scanning Electron Microscopy (SEM) images of the micro and nanostructured and untreated plates are shown. The images were taken using a JEOL JIB 4601F MultiBeam platform. Figure $3 \mathrm{~b}$ illustrates a higher magnification image of the micro and nanostructured plate and shows the nanograss layer covered the surface.
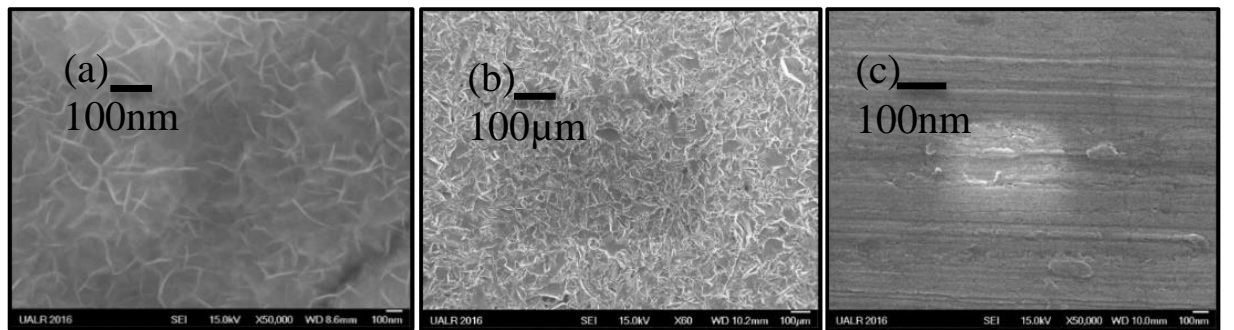

Fig. 2: SEM images of (a), (b) micro and nanostructured plates and (c) untreated plate.

\section{Experimental Setup and Procedure}

The schematic of the experimental setup is demonstrated in Fig. 3. The setup included two storage containers, an Omega $^{\circledR}$ pressure sensor, four Omega ${ }^{\circledR}$ cartridge heaters, an MZR ${ }^{\circledR}-7205$ micro annular gear pump, UNI-T UT325 thermometers, two K-type Omega ${ }^{\circledR}$ thermocouples, an AMETEK Sorensen XHR DC regulated power supply, test section, and proper tubing and fittings. De-ionized water was pumped into the microchannel using the micro gear pump. Mass fluxes were regulated by the micro pump's own controller. The aluminum microchannel with overall dimensions of $14 \mathrm{~cm}$ $\times 1.5 \mathrm{~cm} \times 500 \mu \mathrm{m}$ are shown in Fig. 4. The inlet of the channel was connected to the setup, while the outlet was exposed to the atmosphere to obtain atmospheric conditions at the exit.

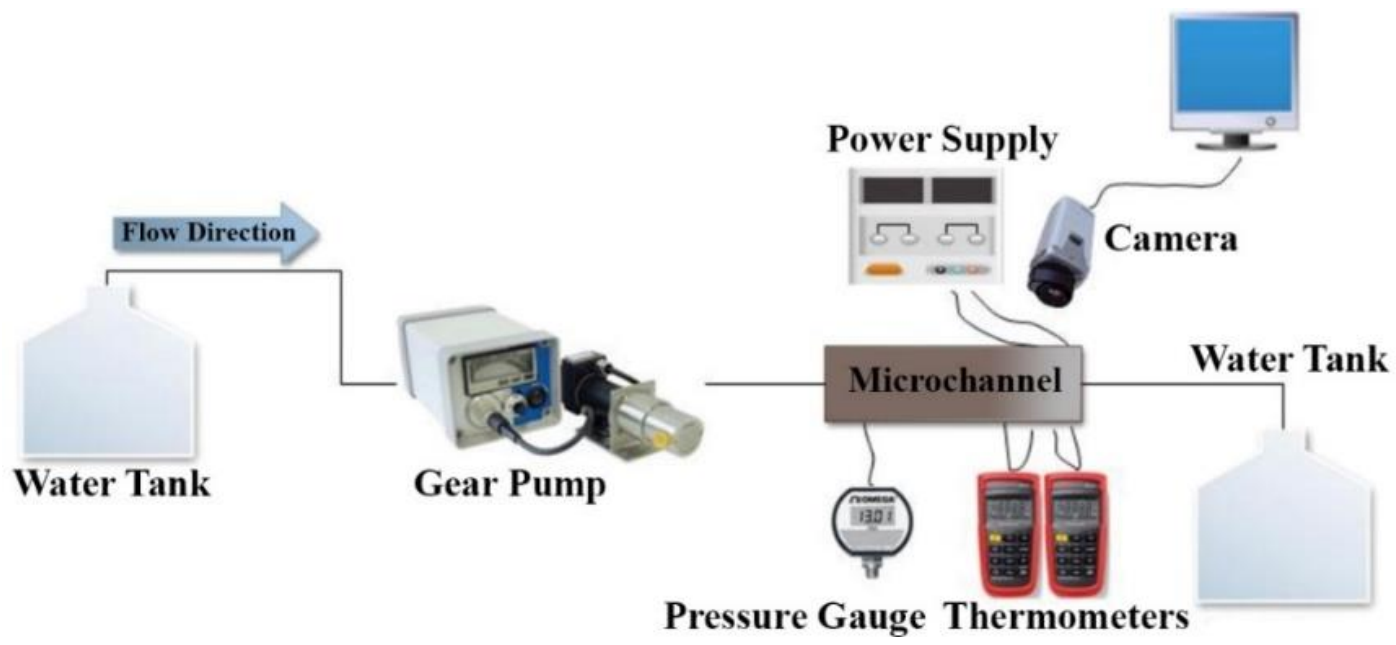

Fig. 3: Schematic representation of the experimental setup.

Four cylindrical cartridge heaters, each having a diameter of $7.5 \mathrm{~mm}$, were inserted into the grooves, with a space of $0.25 \mathrm{~mm}$ from each other, under the microchannel to supply heat flux by applying voltage. The heated length was set as 4 $\mathrm{cm}$, near the exit of the microchannel. As seen from the figure, a square hole of $1.5 \times 1.5 \mathrm{~cm}$ was made near the exit to embed the plates by using a high quality thermal grease. Surface temperatures were measured using K-Type Omega ${ }^{\circledR}$ thermocouples with a diameter of $3 \mathrm{~mm}$ which were connected to the digital thermometers. The local heat transfer coefficients were measured at the middle of the plates. The inlet pressure was measured using a pressure gauge attached to the inlet port. To minimize heat losses, $4 \mathrm{~mm}$ wide air gaps were prepared between the heaters to enclose the heaters with air from all sides. All data collected including power, pressure, and surface temperatures were recorded under steady state conditions. Each experimental run tested for several times to ensure reproducibility of the results. 


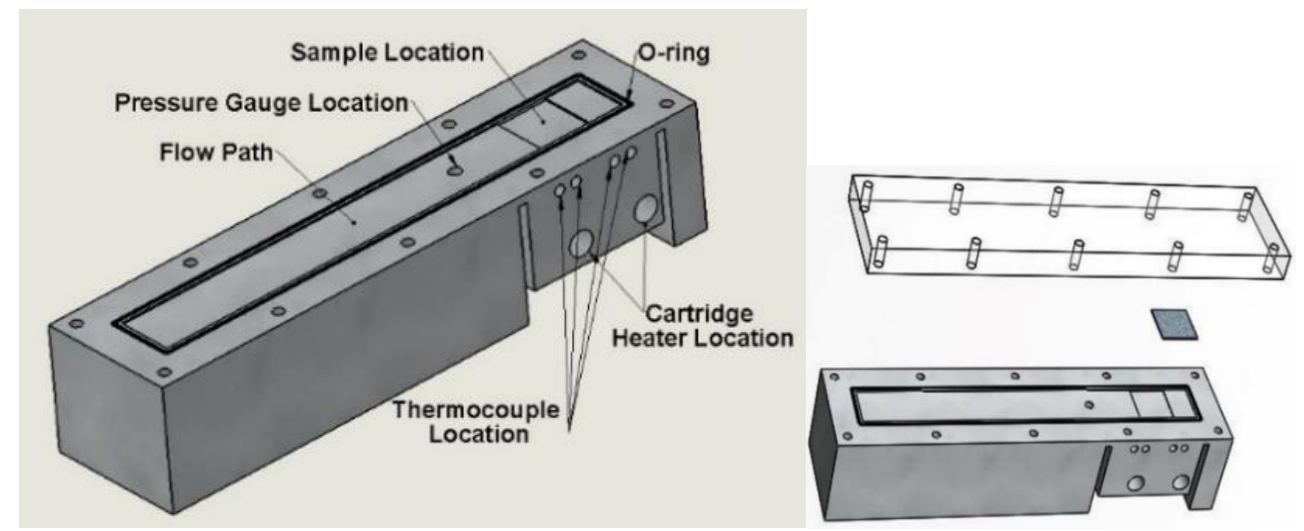

Fig. 4: Schematic illustration of the microchannel.

\section{Data Reduction and Uncertainty Analysis}

The net applied heat flux is defined as:

$$
\mathrm{q}^{\prime \prime}=\frac{\left(\mathrm{P}-\dot{\mathrm{Q}}_{\text {loss }}\right)}{\mathrm{A}}
$$

where $\mathrm{A}$ is the heated surface area. Heat losses, $\dot{\mathrm{Q}}_{\text {loss }}$, were estimated based on the natural convection analysis (Eq. (2)) for surrounding areas of the heater which was subjected to the ambient. The net power was then calculated considering heat loss estimations. The heat losses were as $\sim 20 \%$ due to the low flow rates applied in this study. $A_{s}$ is the surface area of the plate, $\mathrm{T}_{\mathrm{amb}}$ is ambient temperature, and $\mathrm{h}$ is the natural convective heat transfer coefficient.

$$
\dot{\mathrm{Q}}_{\text {loss }}=\mathrm{hA}_{\mathrm{s}}\left(\mathrm{T}_{\mathrm{s}}-\mathrm{T}_{\mathrm{amb}}\right)
$$

The heat transfer coefficient, $\mathrm{h}$, is expressed as:

$$
h=\frac{q^{\prime \prime}}{T_{S}-T_{f}}
$$

where $\mathrm{T}_{\mathrm{f}}$ and $\mathrm{T}_{\mathrm{s}}$ are the bulk fluid and surface temperatures, respectively, which can be calculated as:

$$
\begin{gathered}
\mathrm{T}_{\mathrm{f}}=\mathrm{T}_{\mathrm{i}}+\left[\frac{\left(\mathrm{P}-\mathrm{Q}_{\text {loss }}\right) \mathrm{x}_{\mathrm{th}}}{\left.\dot{\mathrm{m} \mathrm{c}_{\mathrm{p}} \mathrm{L}_{\mathrm{h}}}\right]}\right. \\
\mathrm{T}_{\mathrm{s}}=\mathrm{T}_{\mathrm{th}}-\mathrm{q}^{\prime \prime} \mathrm{R}_{\text {tot }}
\end{gathered}
$$

$\mathrm{T}_{\mathrm{i}}$ is the inlet fluid temperature, $\dot{\mathrm{m}}$ is the mass flow rate, $\mathrm{c}_{\mathrm{p}}$ is specific heat of water, $\mathrm{x}_{\text {th }}$ is thermocouple location, and $\mathrm{L}_{\mathrm{h}}$ is the heated length. $\mathrm{T}_{\text {th }}$ is the thermocouple temperature reading from the thermometer. The surface temperature of the microchannel, $\mathrm{T}_{\mathrm{s}}$, was assessed by evaluating thermal contact resistances generated between the thermocouple and the surface of plates as: 


$$
\mathrm{R}_{\text {tot }}=\mathrm{R}_{\mathrm{tg}}+\mathrm{R}_{\text {plate }}
$$

$R_{\text {tot }}$ is the total thermal resistance calculated by considering the thermal resistance of the grease at the interface between the aluminum base and the plate, $R_{t g}$, and the thermal resistance of the plate, $R_{\text {plate }}$. The Nusselt number for the single phase data is obtained as:

$$
\mathrm{Nu}=\frac{\mathrm{hD}}{\mathrm{k}}
$$

where $D_{h}$ is the hydraulic diameter of the channel and $k$ is the thermal conductivity of water. The flow velocity, $u$, is expressed as:

$$
\mathrm{u}=\frac{\dot{\mathrm{Q}}}{\mathrm{A}_{\mathrm{c}}}
$$

where $\dot{Q}$ is the volumetric flow rate of water and $A_{c}$ is the cross sectional area of the channel. The Reynolds number, $\mathrm{Re}$, is given as:

$$
\operatorname{Re}=\frac{\rho u D_{h}}{\mu}
$$

where $\mu$ is the water dynamic viscosity. The single phase friction factor is found using the classical relation of DarcyWeisbach for fully developed laminar flow as:

$$
\mathrm{f}=\frac{2 \mathrm{D}_{\mathrm{h}} \Delta \mathrm{P} \rho_{\mathrm{f}}}{\mathrm{LG}^{2}}
$$

The uncertainties related to the experimental parameters are shown in Table 1 and were estimated according to the manufacturers' datasheets and the propagation of uncertainty method presented by Kline and McClintock [20].

Table 1: Uncertainties in the experimental parameters.

\begin{tabular}{|c|c|}
\hline Parameters & Uncertainty \\
\hline Power, $\mathrm{P}$ & $\pm 0.15 \%$ \\
\hline Heat transfer coefficient, $\mathrm{h}$ & $\pm 8.4 \%$ \\
\hline Heat flux, $\mathrm{q}$ & $\pm 3.5 \%$ \\
\hline Volumetric flow rate, $\dot{\mathrm{Q}}$ & $\pm 1 \%$ \\
\hline Thermocouple temperature, $\mathrm{T}_{\text {th }}$ & $\pm 0.1^{\circ} \mathrm{C}$ \\
\hline Surface temperature, $\mathrm{T}_{\mathrm{s}}$ & $\pm 0.37^{\circ} \mathrm{C}$ \\
\hline Thermal resistance, $\mathrm{R}_{\text {tot }}$ & $\pm 5 \%$ \\
\hline
\end{tabular}

\section{Results and Discussion}

Single phase tests were performed before conducting systematic experimental runs to check the reliability and accuracy of the setup. Theoretical Nusselt numbers [21] (Eq. 11) and friction factors [22] (Eq. 12) suggested for fully developed laminar flow in rectangular microchannels were compared to the experimental values as plotted in Figs 5(a) and 5(b). 


$$
\mathrm{Nu}=\left[\begin{array}{c}
\left(1.6980 \times 10^{-4}\right) \alpha^{6}-\left(5.7050 \times 10^{-3}\right) \alpha^{5} \\
+\left(7.5552 \times 10^{-2}\right) \alpha^{4}-(0.5054) \alpha^{3} \\
+(1.8448) \alpha^{2}-(3.8559) \alpha+5.2720
\end{array}\right]
$$

where $\alpha$ is aspect ratio of the channel defined as the channel height per channel width.

$$
\mathrm{f}=\frac{82.3}{\operatorname{Re}}
$$

The maximum error of $\sim 20 \%$ obtained for the experimental Nusselt numbers and friction factors with the predictions of the available correlations. The results affirmed that the experimental setup provides accurate and reliable results.
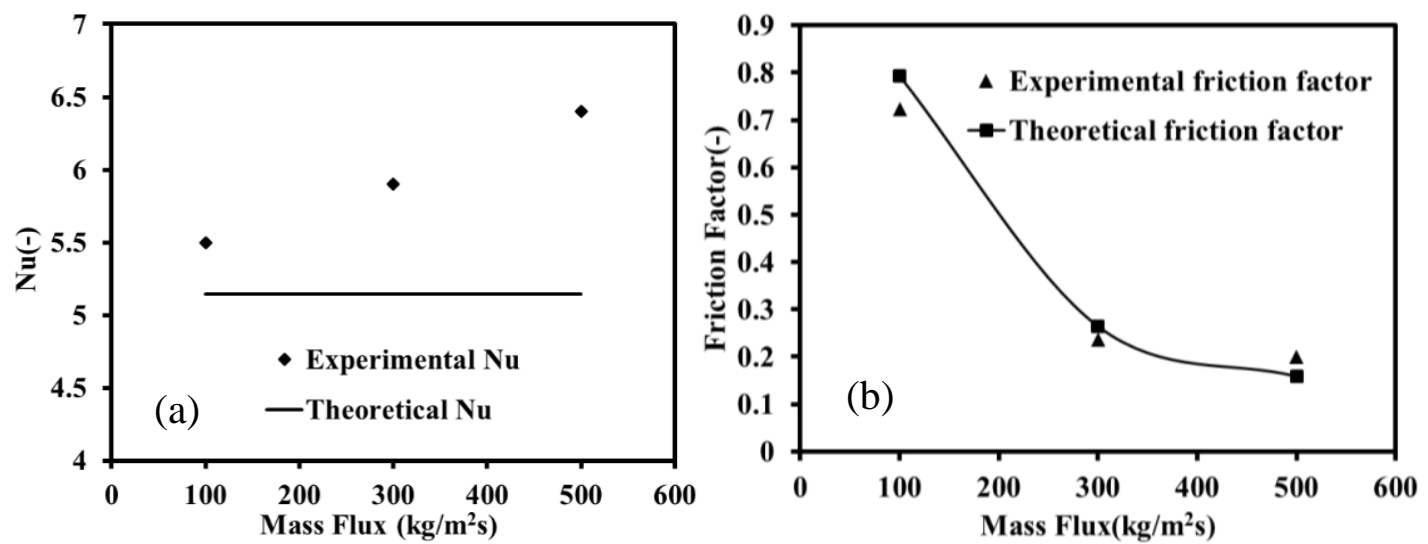

Fig. 5: Single-phase experimental results compared to the existing correlations (a) friction factor and (b) Nusselt number.

\subsection{Boiling Curves and Heat Transfer Results}

Figure 6 illustrates heat flux as a function of wall superheat for the micro and nanostructured and untreated plates at the mass fluxes of 100,300, and $500 \mathrm{~kg} / \mathrm{m} 2 \mathrm{~s}$. As seen from the figures, micro and nanostructured plates sustain about the same heat fluxes compared to the untreated plates at a given wall superheat. It can be also realized that as mass flux increases from 100 to $500 \mathrm{~kg} / \mathrm{m} 2 \mathrm{~s}$, heat flux increases, at the fixed wall superheat.
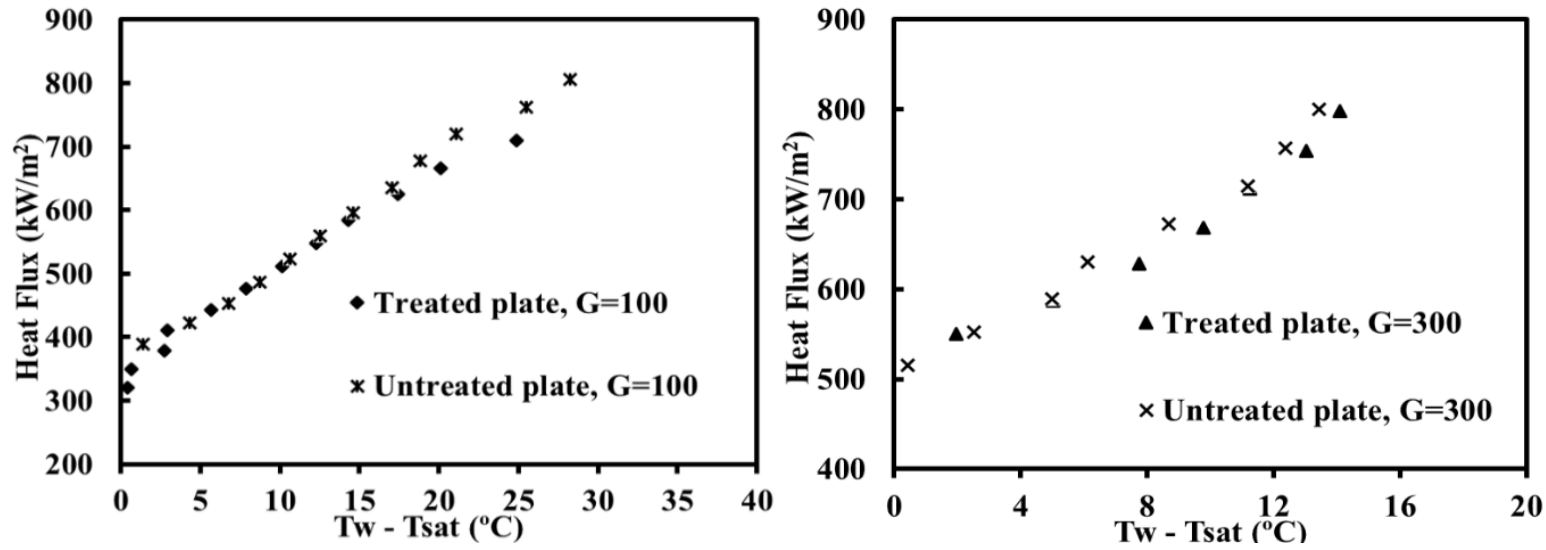


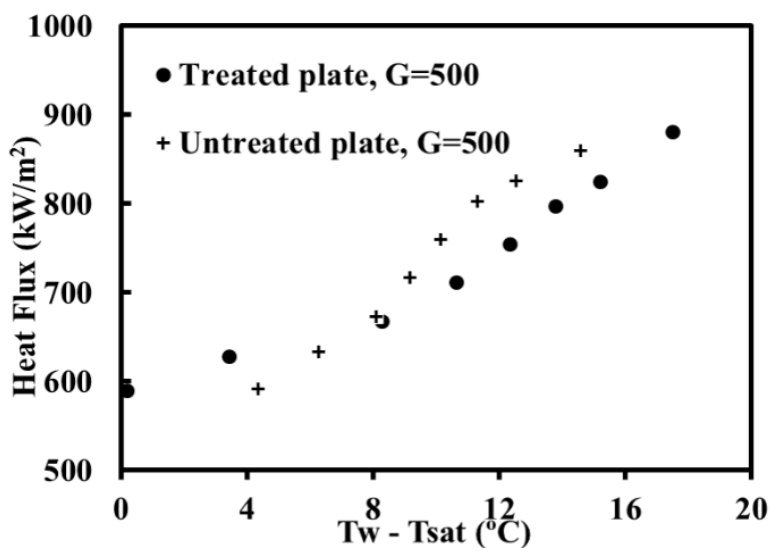

Fig. 6: Heat flux as a function of wall superhaet for the treated and untreated plates at $\mathrm{G}=100,300$, and $500 \mathrm{~kg}$.

Figure 7 illustrates heat transfer versus heat flux for the micro and nanostructured and untreated plates at three mass fluxes of 100,300, and $500 \mathrm{~kg} / \mathrm{m}^{2}$ s. For $\mathrm{G}=100 \mathrm{~kg} / \mathrm{m}^{2} \mathrm{~s}$, it can be seen that heat transfer coefficient increases with heat flux which implies nucleate boiling heat transfer mechanism. Moreover, no significant change in the nucleate boiling heat transfer with the micro and nanostructured plates can be observed compared to the untreated samples. A similar trend exists for the mass fluxes of 300 and $500 \mathrm{~kg} / \mathrm{m}^{2} \mathrm{~s}$.
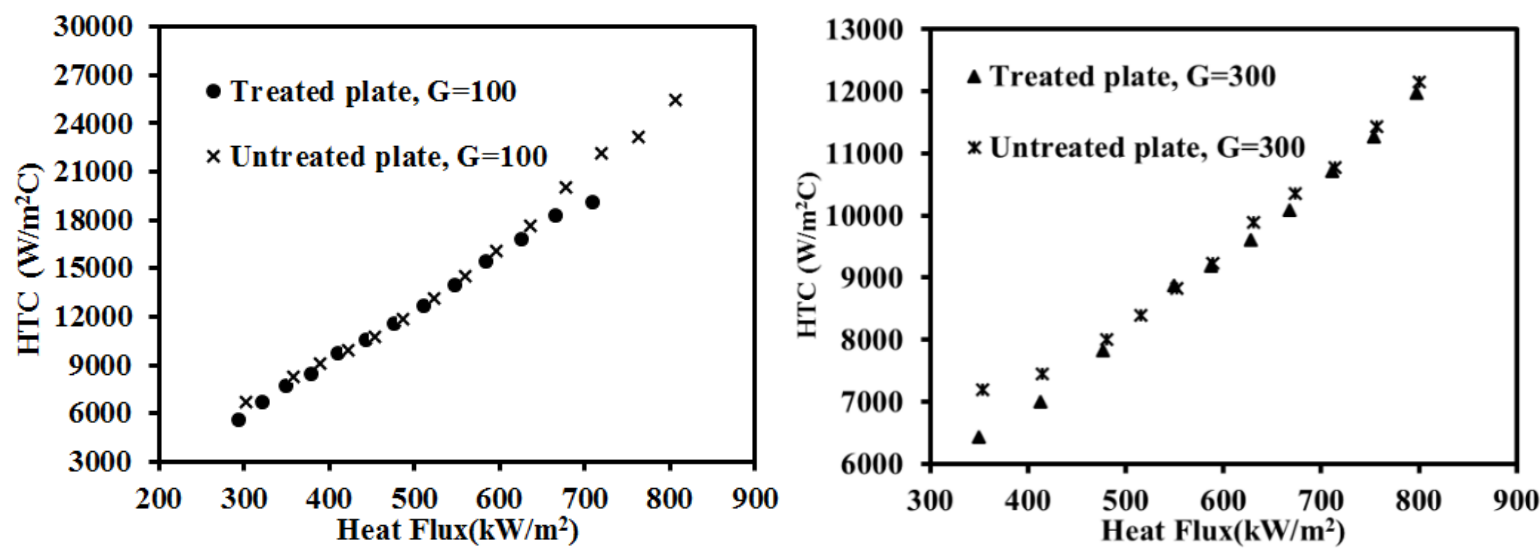


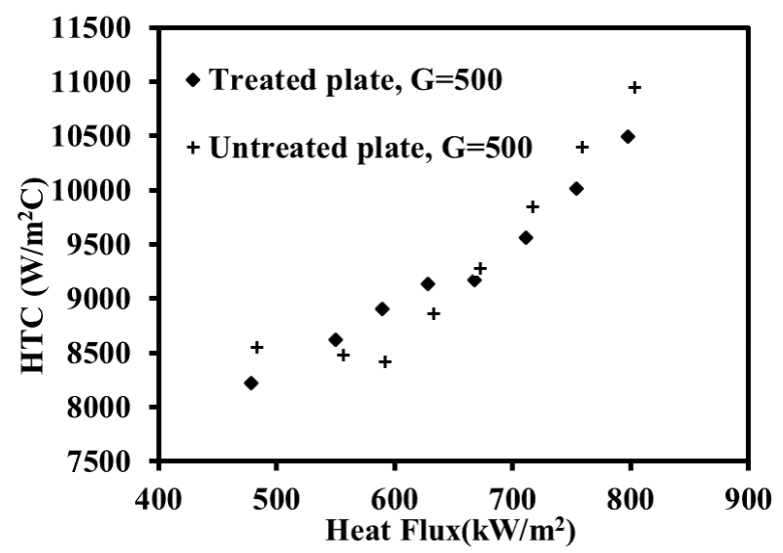

Fig. 7: Heat transfer as a function of heat flux for the treated and untreated plates at $\mathrm{G}=100,300$, and $500 \mathrm{~kg} / \mathrm{m}^{2} \mathrm{~s}$.

High wettability of the micro and nanostructured plates has negative effect on nucleate boiling heat transfer while they have roughness elements, which have a positive effect [23]. As a result of the interplay between these two effects, the heat transfer coefficients are close to each other for both treated and untreated surfaces. The differences between treated and untreated surfaces in HTC are within the uncertainty limits of the experimental data (Table 1). Mass flux does not affect boiling heat transfer in this study, which is expected for nucleate boiling and fully developed boiling region. However, introducing the micro and nanostructures used in this study is expected to extend critical heat flux without sacrificing the nucleate boiling heat transfer [24]. It can be concluded that the micro and nanostructured plates employed in this study are promising for mini/microchannel applications in order to improve thermal management of the cooling systems and extend critical heat flux. Critical heat flux will be investigated on these surfaces as a future study.

\section{Conclusions}

1.The micro and nanostructured plates resulted in almost the same heat transfer coefficients compared to the untreated samples.

2.Heat transfer coefficients were not mass flux dependent implying nucleate boiling heat transfer mechanism.

3. The experimental results proved that the method used for producing the micro and nanostructured plates is efficient and applicable. Besides, it does not negatively affect the environment.

\section{References}

[1] N. T. Nguyen and S. T. Wereley, Fundamentals and Applications of Microfluidics. Artech House, 2002.

[2] S. G. Kandlikar and H. R. Upadhye, "Extending the heat flux limit with enhanced microchannels in direct single phase cooling of computer chips," in Semiconductor Thermal Measurement and Management IEEE Twenty First Annual IEEE Symposium, pp. 8-15, 2005.

[3] S. A. Mousavi Shaegh, N.-T. Nguyen, and S. H. Chan, "A review on membraneless laminar flow-based fuel cells," Int. J. Hydrogen Energy, vol. 36, no. 9, pp. 5675-5694, 2011.

[4] P. J. Berenson, "Experiments on pool-boiling heat transfer," Int. J. Heat Mass Transf., vol. 5, no. 10, pp. 985-999, 1962.

[5] R. J. Benjamin, A. R. Balakrishnan, "Nucleation site density in pool boiling of saturated pure liquids: Effect of surface microroughness and surface and liquid physical properties," Exp. Therm. Fluid Sci., vol. 15, no. 1, pp. 32-42, 1997.

[6] T. Alam, P. S. Lee, and C. R. Yap, "Effects of surface roughness on flow boiling in silicon microgap heat sinks," Int. J. Heat Mass Transf., vol. 64, pp. 28-41, 2013.

[7] V. Wasekar and R. Manglik, "A review of enhanced heat transfer in nucleate pool boiling of aqueous surfactant and polymeric solutions," J. Enhanc. Heat Transf., 1999.

[8] C. N. Ammerman and S. M. You, "Enhancing Small-Channel Convective Boiling Performance Using a Microporous Surface Coating," J. Heat Transfer, vol. 123, no. 5, p. 976, 2001.

[9] M. Nedaei, E. Armagan, M. Sezen, G. O. Ince, A. Kosar, M. Nedaei, E. Armagan, M. Sezen, and G. O. Ince, 
"Enhancemet of flow boiling heat transfer in pHEMA / pPFDA coated microtubes with longitudinal variations in wettability Enhancemet of flow boiling heat transfer in pHEMA / pPFDA coated microtubes with longitudinal variations in wettability," AIP Adv., vol. 6, no. 3, p. 35212, 2016.

[10] M. Nedaei, A. Motezakker, M. Zeybek, and M. Sezen, "Subcooled flow boiling heat transfer enhancement using polyperfluorodecylacrylate (pPFDA) coated microtubes with different coating thicknesses," Exp. Therm. Fluid Sci., 2017.

[11] Y. Sun, L. Zhang, H. Xu, and X. Zhong, "Flow boiling enhancement of FC-72 from microporous surfaces in minichannels," Exp. Therm. Fluid Sci., vol. 35, no. 7, pp. 1418-1426, 2011.

[12] M. Shojaeian, M. Sezen, and A. Koşar, "Pool boiling heat transfer characteristics of non-Newtonian Xanthan gum solutions," Exp. Therm. Fluid Sci., vol. 70, pp. 77-84, 2016.

[13] H. Trieu Phan, N. Caney, P. Marty, S. Colasson, and J. Gavillet, "Flow Boiling of Water on Nanocoated Surfaces in a Microchannel," J. Heat Transfer, vol. 134, no. 2, p. 20901, 2012.

[14] B. Zhang, J. Park, and K. Kim, "Augmented boiling heat transfer on the wetting-modified three dimensionallyinterconnected alumina nano porous surfaces in aqueous polymeric surfactants," Int. J. Heat Mass Transf., 2013.

[15] Y. Yang and J. Maa, "Effects of polymer additives on pool boiling phenomena," Lett. Heat Mass Transf., 1982.

[16] D. Paul and S. Abdel-Khalik, "Nucleate boiling in drag-reducing polymer solutions," J. Rheol. (N. Y. N. Y)., 1983.

[17] B. Bhushan, "Biomimetics: lessons from nature--an overview," Philos. Trans. A. Math. Phys. Eng. Sci., vol. 367, no. 1893, pp. 1445-86, 2009.

[18] M. Nosonovsky and B. Bhushan, "Multiscale friction mechanisms and hierarchical surfaces in nano- and biotribology," Mater. Sci. Eng. R Reports, vol. 58, no. 3-5, pp. 162-193, 2007.

[19] J. Drelich and E. Chibowski, "Superhydrophilic and superwetting surfaces: Definition and mechanisms of control," Langmuir, vol. 26, no. 24, pp. 18621-18623, 2010.

[20] S. Kline and F. McClintock, "Describing uncertainties in single-sample experiments," Mech. Eng., vol. $75,1953$.

[21] V. V. Dharaiya and S. G. Kandlikar, "Numerical Investigation of Heat Transfer in Rectangular Microchannels Under H2 Boundary Condition During Developing and Fully Developed Laminar Flow," J. Heat Transfer, vol. 134, no. 2, p. 20911, 2012.

[22] N. H. Chen, "An Explicit Equation for Friction Factor in Pipe," Ind. Eng. Chem. Fundam., vol. 1, pp. 296-297, 1979.

[23] J. Y. Chang and S. M. Yout, "Enhanced boiling heat transfer from micro-porous surfaces: effects of a coating composition and method," Inf. J. Hear Mass Transf., vol. 40, no. 10, 1997.

[24] K. Chu, Y. S. Joung, R. Enright, C. Buie, "Hierarchically structured surfaces for boiling critical heat flux enhancement," Appl. Phys., 2013. 